\title{
Anthropometry and physical activity level in the prediction of metabolic syndrome in children
}

\author{
Alynne Christian Ribeiro Andaki ${ }^{1, *}$, Adelson Luiz Araújo Tinôco', \\ Edmar Lacerda Mendes ${ }^{2}$, Roberto Andaki Júnior ${ }^{3}$, Andrew P Hills ${ }^{4}$ and \\ Paulo Roberto S Amorim ${ }^{5}$ \\ 'Nutrition and Health Department, Viçosa Federal University, DNS - Prédio CCBII, Sexto andar, \\ Lab. 47 - Campus UFV, Viçosa, MG, 36570-000 Brazil: ${ }^{2}$ Sport Science Department, Triângulo Mineiro Federal \\ University, Uberaba, MG, Brazil: ${ }^{3}$ Physical Education Department, Viçosa Federal University, Viçosa, MG, \\ Brazil: ${ }^{4}$ Mater Mother's Hospital, Mater Medical Research Institute and Griffith Health Institute, Griffith University, \\ Brisbane, Australia: ${ }^{5}$ Physical Education Department, Viçosa Federal University, Viçosa, MG, Brazil
}

Submitted 6 December 2012: Final revision received 23 July 2013: Accepted 14 August 2013: First published online 24 September 2013

\begin{abstract}
Objective: To evaluate the effectiveness of anthropometric measures and physical activity level in the prediction of metabolic syndrome (MetS) in children.

Design: Cross-sectional study with children from public and private schools. Children underwent an anthropometric assessment, blood pressure measurement and biochemical evaluation of serum for determination of TAG, HDL-cholesterol and glucose. Physical activity level was calculated and number of steps per day obtained using a pedometer for seven consecutive days.

Setting: Viçosa, south-eastern Brazil.

Subjects: Boys and girls ( $n$ 187), mean age $9 \cdot 90$ (SD 0.7) years.

Results: Conicity index, sum of four skinfolds, physical activity level and number of steps per day were accurate in predicting MetS in boys. Anthropometric indicators were accurate in predicting MetS for girls, specifically BMI, waist circumference measured at the narrowest point and at the level of the umbilicus, four skinfold thickness measures evaluated separately, the sum of subscapular and triceps skinfold thickness, the sum of four skinfolds and body fat percentage. Conclusions: The sum of four skinfolds was the most accurate method in predicting MetS in both genders.
\end{abstract}

Keywords

CVD

Child

Receiver-operating characteristic curve
Metabolic syndrome (MetS) can be considered as a clustering of cardiovascular risk factors and type 2 diabetes. In adults, diagnosis of MetS requires the presence of at least three of the following factors: central obesity, dyslipidaemia (low HDL-cholesterol (HDL-C) and hypertriacylglycerolaemia), hypertension and hyperglycaemia. However, there is no consensus regarding the diagnosis of MetS in children ${ }^{(1)}$. Some of the criteria used have been based on the recommendations of the National Cholesterol Education Program - Adult Treatment Panel III, with appropriate adjustments and specific cut-off points for age and gender ${ }^{(2-4)}$.

For the diagnosis of metabolic risk and the components of MetS, biochemical evaluation has been more commonly used in clinical practice; however, this is invasive, requires trained personnel and is costly. In contrast, anthropometry has been reported as an important tool for both clinical practice and population studies, including the identification and prediction of metabolic risk ${ }^{(5-9)}$.
In the context of epidemiological studies, several have reported gender differences for percentage body fat ${ }^{(10)}$, waist circumference (WC) ${ }^{(11)}$, insulin resistance (by homeostatic model assessment, HOMA-IR) ${ }^{(10)}$ and $\operatorname{MetS}^{(12)}$ in children. Moreover, gender differences have also been reported following an intervention programme designed to control insulin resistance ${ }^{(13)}$ and after a follow-up of 6.6 years for trends of MetS in children ${ }^{(14)}$. The biochemical and anthropometric changes and differential response to intervention programmes between boys and girls suggest the need for separate analyses.

It is widely acknowledged that lifestyle factors (hours of screen viewing, level of physical activity) influence predictors of the MetS ${ }^{(15,16)}$. For example, regular physical activity plays a fundamental role in the prevention and management of obesity, hypertension, dyslipidaemia and insulin resistance ${ }^{(17)}$; however, data regarding the relationship between physical activity level (PAL) and the prediction of MetS in children remain scarce. The present 
study evaluated the effectiveness of anthropometry and PAL in the prediction of MetS in children.

\section{Materials and methods}

\section{Study design and participants}

The present cross-sectional study was conducted in a sample comprising 187 children (106 girls, 56.7\%) of mean age 9.90 (SD 0.7 ) years. To calculate the minimum sample size we employed the equation proposed by Lwanga and Lemeshow ${ }^{(18)}$. Considering the total number of 1049 students in the age group studied, the population total of 72220 , a standard error of $5 \%$ with a $95 \%$ confidence interval, eight schools (25\% of the thirty-two schools with 5 th graders) were randomly selected. All 5 th-grade students in each school were invited to participate in the study, and $74 \cdot 8 \%$ consented with authorization from their parents.

The sample comprised schoolchildren from the urban area of Viçosa, a university town in south-eastern Brazil with a population of $\sim 72220$ inhabitants and an area of $299 \mathrm{~km}^{2}$. The Human Development Index is $0 \cdot 809$, and the index of development of basic education is $5 \cdot 7$ (a score of $6 \cdot 0$ corresponds to a quality of education system comparable to that in developed countries). The service sector is the main component of the local economy and the Gross Domestic Product is \$US 4320 per capita.

\section{Procedures}

Children underwent a comprehensive anthropometric protocol and blood pressure evaluation after the study was approved by the Ethics in Human Research Committee of the Federal University of Viçosa and parental consent was given. Children were provided instructions regarding the completion of a physical activity recall questionnaire and survey questions regarding socio-economic status and lifestyle were completed by parents. Participants also received instructions regarding the necessity to fast for $12 \mathrm{~h}$ in preparation for the collection of blood. All children received instruction on wearing a pedometer prior to wearing it for seven consecutive days.

\section{Antbropometry}

Body weight was assessed with an electronic digital scale (Lumina-02550; Plenna, São Paulo, Brazil) with a precision of $100 \mathrm{~g}$ and height was measured using a portable 2-m anthropometer (Rigor e Técnica, Viçosa, Brazil) with gradations of $0 \cdot 1 \mathrm{~cm}$. Children were measured wearing light clothes and without shoes following standardized procedures ${ }^{(19)}$. BMI was calculated as weight (in kilograms) divided by the square of height (in metres) and children were classified as overweight or obese, according to criteria established by Cole et al. ${ }^{(20)}$.

WC was measured after normal expiration using a flexible and non-elastic 2-m tape (Sanny, São Paulo, Brazil).
All measurements were carried out in triplicate and the average recorded. Measurements were taken at the following anatomic landmarks: (i) at the narrowest point of the waist between the iliac crest and the ribs (WC1) and (ii) at midpoint between the iliac crest and the lower rib (WC2), as recommended by the $\mathrm{WHO}^{(15)}$; and (iii) at the level of the umbilicus (WC3), as recommended by the Anthropometric Standardization Reference Manual ${ }^{(21)}$. The conicity index was calculated from measurements of WC, weight and height, according to a formula proposed by Valdez ${ }^{(22)}$. The purpose of this index was to assess body fat distribution for which cut-off points are not available in children.

Triceps (TST), subscapular (SST), suprailiac (SuST) and biceps (BST) skinfold thicknesses were measured according to standardized techniques using a Lange skinfold calliper (Cambridge Scientific Instruments, Cambridge, MA, USA) which exerts a constant pressure of $10 \mathrm{~g} / \mathrm{m}^{2}$. All measurements were taken on the right side of the body with three non-consecutive replicates of each measurement ${ }^{(23)}$ which were subsequently averaged. The sum of two skinfolds (TST + SST; $\Sigma 2$ ST) and the sum of four skinfolds (TST + SST + SuST + BST; $\Sigma 4$ ST) were also calculated.

The equations proposed by Slaughter et $a l^{(24)}$ were used to calculate percentage body fat $(\% \mathrm{BF})$ and children were classified according to the categories of adiposity proposed by Lohman ${ }^{(25)}$.

\section{Blood pressure}

Blood pressure was measured using a sphygmomanometer according to standardized approaches ${ }^{(26)}$. Only children whose systolic or diastolic blood pressure values exceeded the 90th percentile (according to height, gender and age) in three different measurements were diagnosed with high blood pressure.

\section{Socio-economic status and lifestyle survey}

Parents received a survey developed specifically for the present study, with eighteen closed questions regarding socio-economic status, lifestyle factors and sedentary behaviour.

\section{Physical activity level}

A $3 \mathrm{~d}$ physical activity diary (two weekdays and one weekend day) was completed ${ }^{(27)}$. Activities were classified according to metabolic equivalents of task (MET) into light $(\leq 3.9 \mathrm{MET})$, moderate $(>4$ and $\leq 6.9 \mathrm{MET})$, vigorous ( $\geq 7 \mathrm{MET}$ ) and moderate-to-vigorous ( $>4 \mathrm{MET}$ ) intensity. Children who accumulated at least $60 \mathrm{~min}$ of moderate-to vigorous-intensity physical activity (MVPA) per day achieved the recommendation for a healthy lifestyle ${ }^{(28)}$.

All children wore a pedometer (DX 8897; Pulse Rate Pedometer, Hong Kong, China) and the average number of steps per day was derived across seven consecutive days. 


\section{Blood collection and analyses}

After $12 \mathrm{~h}$ of fasting, blood samples were collected and immediately processed. Serum was analysed using the enzymatic colorimetric method to determine HDL-C, TAG and glucose on an automated haematology analyser (Cobas Mira Plus; Roche, Rotkreuz, Switzerland).

\section{Metabolic syndrome}

In the current study, MetS was diagnosed according to the presence of three or more of the following criteria: (i) $\mathrm{TAG} \geq 100 \mathrm{mg} / \mathrm{dl}$; (ii) HDL-C $<50 \mathrm{mg} / \mathrm{dl}$; (iii) glucose $\geq 110 \mathrm{mg} / \mathrm{dl}$; (iv) WC $\geq 75$ th percentile for age and sex; and (v) blood pressure (diastolic or systolic) $>90$ th percentile adjusted for age, height and sex. The cut-off points adapted to the age of the population studied were chosen according the criteria of de Ferranti et al. ${ }^{(2)}$.

\section{Statistical analysis}

Analyses were performed using the statistical software package SPSS version $17 \cdot 0$ for Windows. The continuous variables were described by means of measurements with central and dispersion tendency, including mean, standard deviation, median, and minimum and maximum values. The categorical variables were described in percentage values.

All variables were tested for normality by the Kolmogorov-Smirnov test. Student's $t$ test was used to compare the means of independent variables with parametric distribution and the Mann-Whitney test was used for the variables having non-parametric distribution. $P<0.05$ was considered for statistical significance.
The Kruskall-Wallis test with Dunn's post hoc test was selected for comparison among the groups on nonparametric distribution.

Measures of association between MetS, lifestyle and biochemical variables were obtained by the $\chi^{2}$ test and odds ratios with their $95 \%$ confidence intervals are presented.

Cut-off points for the variables analysed were suggested through the use of receiver-operating characteristic (ROC) curves. The optimal cut-offs were determined by finding the values that allowed the best balance between sensitivity and specificity. The statistical significance of each analysis was assessed by the area under the ROC curve (AUC) and by the inferior limit of the 95\% confidence interval being higher than $0 \cdot 5^{(29)}$.

\section{Results}

\section{Antbropometry}

Table 1 shows the anthropometric characteristics of the children. Significant differences $(P<0 \cdot 05)$ were observed between boys and girls for all four skinfolds, the sums of

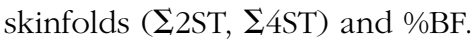

\section{Physical activity level}

The number of steps per day did not differ significantly $(P>0.05)$ between genders, with boys recording a median of 5952 steps/d (range 807-31 459 steps/d) and girls a median of 4906 steps/d (range 387-20 803 steps/d). On the other hand, time spent in MVPA differed significantly $(P<0 \cdot 05)$ between genders: median (range)

Table 1 Anthropometric, biochemical and blood pressure parameters for 5th-grade girls and boys ( $n$ 187; mean age 9.90 (sD 0.7) years), Viçosa, south-eastern Brazil

\begin{tabular}{|c|c|c|c|c|c|c|c|c|c|c|}
\hline & \multicolumn{5}{|c|}{ Girls } & \multicolumn{5}{|c|}{ Boys } \\
\hline & $n$ & Mean & SD & Median & Range & $n$ & Mean & SD & Median & Range \\
\hline Weight (kg) & 106 & $35 \cdot 05$ & $8 \cdot 1$ & $33 \cdot 0$ & $23 \cdot 2-59 \cdot 5$ & 81 & $35 \cdot 10$ & $9 \cdot 4$ & $32 \cdot 4$ & $22 \cdot 6-60 \cdot 1$ \\
\hline Height $(m)$ & 106 & $1 \cdot 40$ & $0 \cdot 7$ & $1 \cdot 4$ & $1 \cdot 3-1 \cdot 6$ & 81 & $1 \cdot 39$ & $0 \cdot 7$ & $1 \cdot 4$ & $1 \cdot 3-1 \cdot 6$ \\
\hline BMI $\left(\mathrm{kg} / \mathrm{m}^{2}\right)$ & 106 & $17 \cdot 56$ & $2 \cdot 9$ & $16 \cdot 9$ & $13 \cdot 7-29 \cdot 1$ & 81 & $17 \cdot 75$ & $3 \cdot 6$ & $16 \cdot 5$ & $13 \cdot 3-28 \cdot 7$ \\
\hline WC1 $(\mathrm{cm})$ & 106 & $59 \cdot 80$ & $6 \cdot 8$ & $57 \cdot 7$ & $51 \cdot 0-82 \cdot 5$ & 81 & $61 \cdot 28$ & $8 \cdot 5$ & $59 \cdot 0$ & $51 \cdot 3-88 \cdot 0$ \\
\hline WC2 (cm) & 106 & $62 \cdot 10$ & $8 \cdot 3$ & $59 \cdot 4$ & $50 \cdot 4-93 \cdot 5$ & 81 & $62 \cdot 20$ & $9 \cdot 2$ & $59 \cdot 7$ & $52 \cdot 0-93 \cdot 2$ \\
\hline WC3 (cm) & 106 & $65 \cdot 21$ & $8 \cdot 7$ & $62 \cdot 5$ & $53 \cdot 2-90 \cdot 7$ & 81 & $64 \cdot 26$ & $10 \cdot 4$ & $61 \cdot 2$ & $44 \cdot 2-94 \cdot 9$ \\
\hline Conicity index & 106 & $1 \cdot 14$ & $0 \cdot 1$ & $1 \cdot 1$ & $1 \cdot 0-2 \cdot 0$ & 81 & $1 \cdot 14$ & $0 \cdot 1$ & $1 \cdot 1$ & $0.9-1.4$ \\
\hline TST $(\mathrm{mm})$ & 106 & $16 \cdot 74^{*}$ & $7 \cdot 2$ & $14 \cdot 8$ & $4 \cdot 8-38 \cdot 7$ & 81 & $14 \cdot 41$ & $8 \cdot 4$ & $12 \cdot 0$ & $4 \cdot 0-41 \cdot 3$ \\
\hline BST (mm) & 106 & $9 \cdot 52^{*}$ & $4 \cdot 6$ & $7 \cdot 3$ & $3 \cdot 0-22 \cdot 0$ & 81 & $8 \cdot 19$ & $6 \cdot 0$ & $6 \cdot 0$ & $3 \cdot 0-31 \cdot 3$ \\
\hline SuST (mm) & 106 & $14 \cdot 95^{\star}$ & $11 \cdot 1$ & $10 \cdot 5$ & $4 \cdot 0-52 \cdot 5$ & 81 & $11 \cdot 78$ & $11 \cdot 0$ & $7 \cdot 5$ & $3 \cdot 0-59 \cdot 0$ \\
\hline SST $(\mathrm{mm})$ & 106 & $11 \cdot 50^{*}$ & $7 \cdot 8$ & $8 \cdot 0$ & $4 \cdot 0-35 \cdot 3$ & 81 & $10 \cdot 33$ & $8 \cdot 7$ & $7 \cdot 0$ & $4 \cdot 0-40 \cdot 0$ \\
\hline$\Sigma 2 S^{\top}(\mathrm{mm})$ & 106 & $28 \cdot 20^{*}$ & $13 \cdot 9$ & $28 \cdot 2$ & $9 \cdot 8-67 \cdot 3$ & 81 & $24 \cdot 74$ & $16 \cdot 6$ & $18 \cdot 7$ & $8 \cdot 0-76 \cdot 3$ \\
\hline$\Sigma 4 S T(\mathrm{~mm})$ & 106 & $52 \cdot 73^{*}$ & $28 \cdot 5$ & $41 \cdot 9$ & $18 \cdot 7-140 \cdot 3$ & 81 & $44 \cdot 69$ & $32 \cdot 9$ & $32 \cdot 0$ & $14 \cdot 0-166 \cdot 7$ \\
\hline$\% B F$ & 106 & $22 \cdot 18^{*}$ & $6 \cdot 1$ & $21 \cdot 1$ & $9 \cdot 3-31 \cdot 5$ & 81 & $18 \cdot 93$ & $6 \cdot 7$ & $17 \cdot 8$ & $7 \cdot 3-31 \cdot 3$ \\
\hline TAG (mg/dl) & 84 & $72 \cdot 65$ & $34 \cdot 3$ & $62 \cdot 0$ & $40 \cdot 0-227 \cdot 0$ & 57 & $60 \cdot 77$ & $18 \cdot 2$ & $57 \cdot 5$ & $41 \cdot 0-120 \cdot 0$ \\
\hline HDL-C (mg/dl) & 84 & $57 \cdot 12$ & $10 \cdot 4$ & $57 \cdot 0$ & $31 \cdot 0-84 \cdot 0$ & 57 & $55 \cdot 54$ & $9 \cdot 2$ & $56 \cdot 0$ & $32 \cdot 0-75 \cdot 0$ \\
\hline Glucose (mg/dl) & 84 & $77 \cdot 87$ & $5 \cdot 0$ & $77 \cdot 0$ & $60 \cdot 0-89 \cdot 0$ & 57 & $79 \cdot 18$ & $5 \cdot 5$ & $78 \cdot 5$ & $70 \cdot 0-96 \cdot 0$ \\
\hline SBP $(m m H g)$ & 106 & $110 \cdot 17$ & $10 \cdot 2$ & $110 \cdot 0$ & $90 \cdot 0-140 \cdot 0$ & 81 & $107 \cdot 03$ & $9 \cdot 8$ & $108 \cdot 0$ & $90 \cdot 0-140 \cdot 0$ \\
\hline DBP $(\mathrm{mmHg})$ & 106 & $73 \cdot 51$ & $7 \cdot 5$ & $70 \cdot 0$ & $60 \cdot 0-100 \cdot 0$ & 81 & $72 \cdot 25$ & $7 \cdot 5$ & $70 \cdot 0$ & $56 \cdot 0-100 \cdot 0$ \\
\hline
\end{tabular}

WC1, waist circumference taken at the narrowest point of the waist, between the iliac crest and the ribs; WC2, waist circumference taken at the midpoint between the iliac crest and the lower rib; WC3, waist circumference taken at the level of the umbilicus; TST, triceps skinfold thickness; BST, biceps skinfold thickness; SuST, suprailiac skinfold thickness; SST, subscapular skinfold thickness; $\Sigma 2 S T$, sum of two skinfolds (TST + SST); $\Sigma 4 S T$, sum of four skinfolds (TST + SST + SuST + BST); \%BF, percentage body fat; HDL-C, HDL-cholesterol; SBP, systolic blood pressure; DBP, diastolic blood pressure.

${ }^{*}$ Significant differences between genders, Mann-Whitney test $(P<0 \cdot 05)$. 
Table 2 Cut-off points for predictors of MetS in 5th-grade boys $(n$ 81), Viçosa, south-eastern Brazil

\begin{tabular}{|c|c|c|c|c|c|}
\hline & Cut-off point & SENS (\%) & SPEC (\%) & PPV (\%) & NPV (\%) \\
\hline \multicolumn{6}{|l|}{ Anthropometric } \\
\hline Conicity index & $>1 \cdot 16$ & 100 & $45 \cdot 1$ & $12 \cdot 5$ & 100 \\
\hline$\Sigma$ SST $(\mathrm{mm})$ & $>68 \cdot 8$ & 100 & $82 \cdot 3$ & $30 \cdot 8$ & 100 \\
\hline \multicolumn{6}{|l|}{ Non-anthropometric } \\
\hline Number of steps/d & 7872 & 100 & $78 \cdot 2$ & $22 \cdot 0$ & 100 \\
\hline
\end{tabular}

MetS, metabolic syndrome; $\Sigma 4 S T$, sum of four skinfolds (triceps + subscapular + suprailiac + biceps); SENS, sensitivity; SPEC, specificity; PPV, positive predictive value; NPV, negative predictive value.

of $105 \mathrm{~min} / \mathrm{d}(0-390 \mathrm{~min} / \mathrm{d})$ and $15 \mathrm{~min} / \mathrm{d}(0-360 \mathrm{~min} / \mathrm{d})$ for boys and girls, respectively.

Only $13 \cdot 6 \%$ of girls and $14.5 \%$ of boys achieved the American recommendation of 11000 and 13000 steps/d, respectively ${ }^{(30)}$, and $36.7 \%$ of girls and $68 \cdot 1 \%$ of boys met the recommended $60 \mathrm{~min}$ of daily $\mathrm{MVPA}^{(28)}$.

\section{Biochemical variables and blood pressure}

None of the participants had impaired fasting glucose, $24 \cdot 1 \%$ of the children had HDL-C levels below the recommended level, $10 \cdot 6 \%$ had hypertriacylglycerolaemia and $14.4 \%$ recorded high blood pressure. For all biochemical variables and blood pressure, no significant betweengender differences were found $(P>0 \cdot 05$; see Table 1$)$.

\section{Metabolic syndrome}

MetS was found in $8.5 \%$ of the children. In respect of the five components of MetS (TAG, HDL-C, glucose, WC and blood pressure), $53 \cdot 2 \%$ of children showed normal values in all measures while $26 \cdot 2 \%$ had at least one component, $12 \cdot 1 \%$ had two components, $6 \cdot 4 \%$ had three, and $2 \cdot 1 \%$ had four or more components of MetS.

The prevalence of overweight and obesity was $15 \cdot 0 \%$ and $5.9 \%$, respectively, with boys showing a higher obesity prevalence $(8.6 \%)$ than girls $(3 \cdot 8 \%)$.

For girls, hypertriacylglycerolaemia and high $\% \mathrm{BF}$ were significantly associated with MetS (OR $=31 \cdot 3$; 95\% CI $5 \cdot 43,179)$ and (OR $=6 \cdot 23 ; 95 \%$ CI $1 \cdot 03,48 \cdot 3)$, respectively. For boys, significant associations were found for MetS and hypertriacylglycerolaemia $(\mathrm{OR}=47 \cdot 0 ; 95 \% \mathrm{CI}$ $3 \cdot 68,599)$ and MetS and low HDL-C (OR $=34 \cdot 5 ; 95 \% \mathrm{CI}$ $2 \cdot 80,413)$. There was no significant association between screen time (hours in front of a television and computer) and MetS.

\section{Predictors of the metabolic syndrome}

Anthropometric indices presented in Table 1 were tested as predictors of MetS in both genders. For boys, the AUC was significant for conicity index (AUC $=0.737 ; 95 \% \mathrm{CI}$ $0.520,0.955)$ and $\Sigma 4$ ST (AUC $=0.897 ; 95 \%$ CI 0.785 , 0.963). Weight, height, BMI, WC, the four skinfolds assessed separately, $\Sigma 2 \mathrm{ST}$ and $\% \mathrm{BF}$ were ruled out as predictors of MetS in boys. Cut-off points for anthropometric measures were suggested for boys that showed the best balance between sensitivity and specificity (Table 2).
Table 3 Area under the ROC curve of anthropometric predictors of MetS in 5th-grade girls ( $n$ 106), Viçosa, south-eastern Brazil

\begin{tabular}{|c|c|c|c|}
\hline Anthropometric index & AUC & SE & $95 \% \mathrm{Cl}$ \\
\hline BMI $\left(\mathrm{kg} / \mathrm{m}^{2}\right)$ & $0 \cdot 754^{*}$ & 0.084 & $0.590,0.919$ \\
\hline WC1 $(\mathrm{cm})$ & $0 \cdot 683^{*}$ & 0.086 & $0.516,0.852$ \\
\hline WC3 (cm) & $0 \cdot 709^{\star}$ & 0.095 & $0.522,0.896$ \\
\hline TST (mm) & $0 \cdot 737^{\star}$ & 0.104 & $0.633,0.826$ \\
\hline BST (mm) & $0 \cdot 674^{\star}$ & $0 \cdot 109$ & $0.566,0.770$ \\
\hline SuST $(\mathrm{mm})$ & $0.667^{*}$ & $0 \cdot 109$ & $0.559,0.764$ \\
\hline SST (mm) & $0 \cdot 708^{*}$ & $0 \cdot 107$ & $0.601,0.800$ \\
\hline$\Sigma 2 \mathrm{ST}(\mathrm{mm})$ & $0 \cdot 733^{*}$ & $0 \cdot 105$ & $0.628,0.822$ \\
\hline$\Sigma 4 \mathrm{ST}(\mathrm{mm})$ & $0.908^{\star}$ & 0.070 & $0.827,0.959$ \\
\hline$\% B F$ & $0 \cdot 788^{*}$ & 0.065 & $0.660,0.916$ \\
\hline
\end{tabular}

ROC, receiver-operating characteristic; MetS, metabolic syndrome; AUC, area under the curve; WC1, waist circumference taken at the narrowest point of the waist, between the iliac crest and the ribs; WC3, waist circumference taken at the level of the umbilicus; TST, triceps skinfold thickness; BST, biceps skinfold thickness; SuST, suprailiac skinfold thickness; SST, subscapular skinfold thickness; $\Sigma 2 \mathrm{ST}$, sum of two skinfolds (TST + SST); $\Sigma 4 S T$, sum of four skinfolds (TST + SST + SuST + BST); $\% \mathrm{BF}$, percentage body fat.

*Significant AUC, inferior limit to the $95 \% \mathrm{Cl}$ greater than 0.5 .

For girls, anthropometric measures including BMI, WC1, WC3, four skinfolds assessed separately, ¿2ST, $\Sigma$ STT (higher AUC $=0.908$ ) and \%BF (Table 3) were useful for the prediction of MetS, and cut-off points were proposed for these measures (Table 4).

The number of steps per day was an accurate predictor of MetS, acting as a protective factor in boys (AUC $=0.891 ; 95 \%$ CI $0.736,0.971$ ). Cut-off points with the best balance between sensitivity and specificity for protection against MetS are shown in Table 2. However, the number of steps per day by girls and the time spent in MVPA for both genders were not accurate in predicting MetS.

\section{Discussion}

The present study proposes a simple, easily applied, reproducible and low-cost alternative for the prediction of MetS in children. Currently, there is no consensus regarding the most appropriate anthropometric, haemodynamic and biochemical parameters to diagnose MetS in children. Accordingly, the present study sought to elucidate the accuracy of anthropometric parameters to diagnose the MetS. 
Table 4 Cut-off points for anthropometric predictors of MetS in 5th-grade girls ( $n$ 106), Viçosa, south-eastern Brazil

\begin{tabular}{|c|c|c|c|c|c|}
\hline Anthropometric index & Cut-off point & SENS (\%) & SPEC (\%) & PPV (\%) & NPV (\%) \\
\hline BMI $\left(\mathrm{kg} / \mathrm{m}^{2}\right)$ & $>19 \cdot 2$ & 50 & $78 \cdot 75$ & $19 \cdot 0$ & $94 \cdot 0$ \\
\hline$W_{C 1}(\mathrm{~cm})$ & $>56 \cdot 0$ & 100 & $40 \cdot 00$ & $14 \cdot 3$ & 100 \\
\hline WC3 $(\mathrm{cm})$ & $>63 \cdot 8$ & 75 & $61 \cdot 25$ & $16 \cdot 2$ & $96 \cdot 1$ \\
\hline TST (mm) & $>14 \cdot 8$ & 100 & $53 \cdot 75$ & $17 \cdot 8$ & 100 \\
\hline BST $(\mathrm{mm})$ & $>8.2$ & 75 & $56 \cdot 25$ & $14 \cdot 6$ & $95 \cdot 7$ \\
\hline SuST (mm) & $>8 \cdot 3$ & 100 & $45 \cdot 00$ & $15 \cdot 4$ & 100 \\
\hline SST (mm) & $>7.6$ & 100 & $48 \cdot 75$ & $16 \cdot 3$ & 100 \\
\hline ¿2ST (mm) & $>22 \cdot 6$ & 100 & $52 \cdot 50$ & $17 \cdot 4$ & 100 \\
\hline$\Sigma 4 S T(\mathrm{~mm})$ & $>72 \cdot 0$ & 100 & $82 \cdot 50$ & $36 \cdot 4$ & 100 \\
\hline$\% \mathrm{BF}$ & $>25.7$ & 75 & $71 \cdot 25$ & $20 \cdot 7$ & $96 \cdot 6$ \\
\hline
\end{tabular}

MetS, metabolic syndrome; WC1, waist circumference taken at the narrowest point of the waist, between the iliac crest and the ribs; WC3, waist circumference taken at the level of the umbilicus; TST, triceps skinfold thickness; BST, biceps skinfold thickness; SuST, suprailiac skinfold thickness; SST, subscapular skinfold thickness; $\Sigma 2 S T$, sum of two skinfolds (TST + SST); $\Sigma 4 S T$, sum of four skinfolds (TST + SST + SuST + BST); \%BF, percentage body fat; SENS, sensitivity; SPEC, specificity; PPV, positive predictive value; NPV, negative predictive value.

¿4ST was the main anthropometric predictor of MetS in boys and girls (AUC $=0.897$ and $\mathrm{AUC}=0.908$, respectively) and showed cut-off point values with sensitivity and specificity above $80 \%$. It is worth noting that the closer to $1 \cdot 0$ is the AUC, the more accurate and the higher the power of a diagnostic test.

$\Sigma$ 2ST was accurate in only girls (AUC $=0 \cdot 733$ ). Freedman et al. $^{(5)}$ reported that $\Sigma$ 2ST had lower accuracy than BMI in predicting cardiovascular risk factor components of MetS, in agreement with data from the present study (Table 4).

Several studies have emphasized the relationship between TST and \% $\mathrm{BF}^{(31-35)}$; however, studies investigating the power of TST to predict MetS remain scarce. Our results demonstrated that all individual skinfold thickness measures predict MetS in girls. Among these, TST is more accurate (AUC $=0 \cdot 737 ; 95 \%$ CI $0 \cdot 633,0 \cdot 826$; sensitivity $=100 \%$, specificity $=53 \cdot 75 \%$ ) with a cut-off point of $14.8 \mathrm{~mm}$. Sardinha et al. ${ }^{(32)}$ reported that TST is also efficient in predicting \%BF in 10-11-year-old girls (against the gold standard of dual energy X-ray absorptiometry) and obtained an AUC of 0.96 (95\% CI $0 \cdot 87, \quad 0 \cdot 99 ;$ sensitivity $=79 \%$, specificity $=100 \%$ with a cut-off point of $21 \mathrm{~mm}$. Moreover, this cut-off point predicts increases in total cholesterol and LDL-cholesterol (sensitivity $=83 \cdot 3 \%$, specificity $=78 \cdot 7 \%$ ) for 11 -year-old Brazilian boys ${ }^{(36)}$. Given this evidence, measurement of TST is an important indicator of cardiovascular risk factors and should be included in both scientific research and the clinical monitoring of children.

In the present study, the cut-off point suggested for $\% \mathrm{BF}$ in the prediction of MetS in girls was $25.7 \%$ (sensitivity $=75 \%$, specificity $=71 \cdot 25 \%$ ), a value similar to the one proposed by Lohman ${ }^{(31)}$ to classify girls with moderately high $\% \mathrm{BF}(\% \mathrm{BF} \geq 25 \%$ ). Thus, $\% \mathrm{BF}>25 \%$ for girls seems to be confirmed as a key value in increasing the risk for developing MetS.

To our knowledge, the present study is the first to suggest a conicity index cut-off point as a predictor of MetS in Brazilian children. The conicity index was accurate in the prediction of MetS for boys only, with a cut-off point of $1 \cdot 16$ (AUC $=0 \cdot 737 ; 95 \%$ CI $0 \cdot 520,0 \cdot 955$ ). The conicity index predominantly assesses central fat that is highly correlated with components of the $\operatorname{MetS}^{(37)}$. However, as the conicity index was created for adults and with sex-specific cut-off points, its use in children has remained somewhat controversial. Taylor et $a l .{ }^{(38)}$ tested the accuracy of three anthropometric measures in predicting the percentage of central fat in children and adolescents (3-19 years old). The conicity index had lower accuracy (AUC $=0 \cdot 81 ; 95 \%$ CI $0 \cdot 74,0 \cdot 88)$ compared with WC (AUC $=0.97 ; 95 \%$ CI $0.95,0.99)$ and greater accuracy in relation to the waist-to-hip ratio (AUC $=0 \cdot 71 ; 95 \%$ CI $0 \cdot 62,0 \cdot 80$ ). The median value for the conicity index was $1 \cdot 16$ and did not show the value of the cut-off point ${ }^{(38)}$. Alternatively, the conicity index is a simple and, in the absence of sophisticated equipment, can be used as a measure of body fat distribution in children $^{(39)}$.

The BMI is widely reported as a diagnostic tool for obesity. As an indicator of MetS in children, numerous cut-off points have been suggested for BMI: $>97$ th percentile for age and $\operatorname{sex}^{(40-42)}$; $\geq 85$ th percentile ${ }^{(43)}$; and the cut-off point proposed by Cole et $a l^{(20)}$ to define overweight and obesity ${ }^{(44)}$. We suggest, for girls, a BMI cut-off point of $19 \cdot 2 \mathrm{~kg} / \mathrm{m}^{2}$ (sensitivity $=50 \%$, specificity $=78 \cdot 25 \%$, approaching the values of Cole et al. $\left(\mathrm{BMI}=19 \cdot 86 \mathrm{~kg} / \mathrm{m}^{2}\right)$ and Conde and Monteiro $\left(\mathrm{BMI}=18.63 \mathrm{~kg} / \mathrm{m}^{2}\right)^{(45)}$, a national reference for the diagnosis of overweight in 10-year-old girls. In a case-control study $^{(46)}$, only $12 \%$ of the overweight/obese group were free of MetS risk factors in contrast to $83.9 \%$ of normalweight children. These findings underline the importance of BMI as a predictor of MetS risk.

As an indicator of MetS, WC is assessed with the largest number of methodological variations. Different points of measurement were detected and cut-offs points have varied: $\geq 85$ th percentile of the population studied ${ }^{(47)}$ and $\geq 90$ th percentile for age and $\operatorname{sex}^{(42,43)}$. In the present study, two measurement sites were accurate in predicting 
MetS in girls: WC1 and WC3, with cut-off points of $56 \cdot 0$ and $63.8 \mathrm{~cm}$, respectively, in the prediction of MetS. WC3 was more accurate (AUC $=0 \cdot 709$ ) with a better balance between sensitivity and specificity compared with WC1 (AUC $=0 \cdot 683$ ).

Hirschler et al. ${ }^{(6)}$ reported that WC3 correlated significantly with all components of MetS in children aged 6-13 years. Furthermore, they highlighted that children with abdominal obesity ( $>90$ th percentile of the sample) had increased risk for CVD and type 2 diabetes. In the current study, we observed that $10 \cdot 1 \%$ of children were $>90$ th percentile for abdominal obesity (WC3 $>78 \cdot 68 \mathrm{~cm}$ ). On the other hand, when using the cut-off point suggested (WC3 $>63.8 \mathrm{~cm}$ ) for the prediction of MetS, an estimated $38.7 \%$ of children were at risk of MetS.

The current study is the first to suggest a cut-off point for the number of steps per day as a predictor of MetS in Brazilian boys. Use of this indicator suggested that $40 \%$ of boys studied were protected from MetS based on attainment of the recommended cut-off point of 7872 steps/d $(\mathrm{AUC}=0 \cdot 891 ; 95 \%$ CI $0 \cdot 736,0.971 ;$ sensitivity $=100 \%$; specificity $=78 \cdot 12 \%$ ). The ROC curve analysis demonstrated better sensitivity and specificity with much lower values of steps/d compared with the American recommendation of 13000 steps/d to achieve a minimum standard of health ${ }^{(30)}$. All children classified as having MetS achieved less than 7872 steps/d, indicating that this number of steps may be a critical marker of poor metabolic health.

There is an urgent need to establish criteria to facilitate the diagnosis of MetS in children and recommended cutoff points should be similar to those of adults to facilitate comparisons ${ }^{(3)}$. Current recommendations and cut-off points need to be developed and reviewed, particularly for WC, dyslipidaemia and hyperglycaemia.

Our data provide evidence for the incorporation of a comprehensive tool to be used by health workers and educators involved in health programmes for schoolchildren. As Brazil has a government-endorsed School Health Program target to evaluate students, the findings of the present study provide justification for the addition of a physical assessment to assist in the prediction of schoolchildren at risk of MetS.

The power of the results related to the anthropometric measures presented herein support their use in screening children at risk of poor metabolic health. Most importantly, a large number of children could be assessed inexpensively, those at risk diagnosed early, and referred to the appropriate professionals for assistance.

\section{Conclusion}

We conclude that, for both genders, $\Sigma$ 4ST was the most accurate method to predict MetS in children. Moreover, BMI and WC, already widely used in the diagnosis of
MetS, were accurate in the prediction of MetS only in girls. PAL and the number of steps per day, however, were effective in the prediction of MetS in boys. Thus, monitoring of anthropometric measures and PAL is essential in the control and prevention of MetS in children.

\section{Acknowledgements}

Sources of funding: This research received no specific grant from any funding agency in the public, commercial or not-for-profit sectors. Conflicts of interest: All authors declare that there are no conflicts of interest. Ethical approval: The protocol for the research project was approved by the Federal University of Viçosa Human Research Ethics Committee and conformed to the provisions of the Declaration of Helsinki in 1995 (as revised in Edinburgh 2000). All participants gave informed consent and participant anonymity has been preserved. Authors' contributions: A.C.R.A. conceived the manuscript, performed the statistical analyses, interpreted the data and drafted the manuscript. A.L.A.T. partly contributed to the conception and design of the current study, provided statistical expertise and critical revision. E.L.M. partly contributed to the conception and design of the current study, provided statistical expertise and critical revision. R.A.J. performed the statistical analyses, interpreted the data and drafted the manuscript. A.P.H. revised English, contributed to the analyses and interpretation of the data and provided critical revision of the manuscript. P.R.S.A. revised English and partly contributed to the conception and design of the current study, contributed to the analyses and interpretation of the data and provided critical revision of the manuscript. All authors provided critical feedback on drafts and read and approved the final manuscript. Acknowledgements: The authors wish to thank the children for their participation in the study, as well as their parents for their cooperation.

\section{References}

1. Lee S, Bacha F, Gungor N et al. (2008) Comparison of different definitions of pediatric metabolic syndrome: relation to abdominal adiposity, insulin resistance, adiponectin, and inflammatory biomarkers. J Pediatr 152, $177-184$.

2. de Ferranti SD, Gauvreau K, Ludwig DS et al. (2004) Prevalence of the metabolic syndrome in American adolescents: findings from the Third National Health and Nutrition Examination Survey. Circulation 110, 2494-2497.

3. Cruz ML \& Goran MI (2004) The metabolic syndrome in children and adolescents. Curr Diab Rep 4, 53-62.

4. Cook S, Weitzman M, Auinger P et al. (2003) Prevalence of a metabolic syndrome phenotype in adolescents: findings from the third National Health and Nutrition Examination Survey, 1988-1994. Arch Pediatr Adolesc Med 157, 821-827.

5. Freedman DS, Katzmarzyk PT, Dietz WH et al. (2009) Relation of body mass index and skinfold thicknesses to 
cardiovascular disease risk factors in children: the Bogalusa Heart Study. Am J Clin Nutr 90, 210-216.

6. Hirschler V, Aranda C, Calcagno Mde L et al. (2005) Can waist circumference identify children with the metabolic syndrome? Arch Pediatr Adolesc Med 159, 740-744.

7. Hirschler V, Roque MI, Calcagno ML et al. (2007) Maternal waist circumference and the prediction of children's metabolic syndrome. Arch Pediatr Adolesc Med 161, $1205-1210$

8. Janssen I, Katzmarzyk PT, Srinivasan SR et al. (2005) Utility of childhood BMI in the prediction of adulthood disease: comparison of national and international references. Obes Res 13, 1106-1115.

9. Agirbasli M, Agaoglu NB, Ergonul O et al. (2011) Comparison of anthropometric indices in predicting metabolic syndrome components in children. Metab Syndr Relat Disord 9, 453-459.

10. Raman A, Fitch MD, Hudes ML et al. (2008) Baseline correlates of insulin resistance in inner city high-BMI African-American children. Obesity (Silver Spring) 16, 2039-2045.

11. Moreno LA, Fleta J, Mur L et al. (1999) Waist circumference values in Spanish children - gender related differences. Eur J Clin Nutr 53, 429-433.

12. Friend A, Craig L \& Turner S (2013) The prevalence of metabolic syndrome in children: a systematic review of the literature. Metab Syndr Relat Disord 11, 71-80.

13. Raman A, Ritchie LD, Lustig RH et al. (2010) Insulin resistance is improved in overweight African American boys but not in girls following a one-year multidisciplinary community intervention program. J Pediatr Endocrinol Metab 23, 109-120.

14. Barzin M, Hosseinpanah F, Saber H et al. (2012) Gender differences time trends for metabolic syndrome and its components among Tehranian children and adolescents. Cholesterol 2012, 804643.

15. Hong HR, Kim SU \& Kang HS (2009) Physical activity and metabolic syndrome in Korean children. Int J Sports Med 30, 677-683.

16. Casazza K, Dulin-Keita A, Gower BA et al. (2009) Differential influence of diet and physical activity on components of metabolic syndrome in a multiethnic sample of children. J Am Diet Assoc 109, 236-244.

17. Steinberger J, Daniels SR, Eckel RH et al. (2009) Progress and challenges in metabolic syndrome in children and adolescents: a scientific statement from the American Heart Association Atherosclerosis, Hypertension, and Obesity in the Young Committee of the Council on Cardiovascular Disease in the Young; Council on Cardiovascular Nursing; and Council on Nutrition, Physical Activity, and Metabolism. Circulation 119, 628-647.

18. Lwanga SK \& Lemeshow S (1991) Sample Size Determination in Health Studies: A Practical Manual. Geneva: WHO.

19. World Health Organization (1995) Physical Status: The Use and Interpretation of Anthropometry. Report of a WHO Expert Committee. WHO Technical Report Series no. 854. Geneva: WHO.

20. Cole TJ, Bellizzi MC, Flegal KM et al. (2000) Establishing a standard definition for child overweight and obesity worldwide: international survey. BMJ 320, 1240-1243.

21. Lohman TG, Roche AF \& Martorell R (1988) Anthropometric Standardization Reference Manual. Champaign, IL: Human Kinetics

22. Valdez R (1991) A simple model-based index of abdominal adiposity. J Clin Epidemiol 44, 955-956.

23. Guedes DPG \& Guedes JERP (2006) Manual Prático para Avaliação em Educação Física. Barueri, SP: Manole.

24. Slaughter MH, Lohman TG, Boileau RA et al. (1988) Skinfold equations for estimation of body fatness in children and youth. Hum Biol 60, 709-723.
25. Lohman $\mathrm{T}$ (1987) The use of skinfolds to estimate body fatness on children and youth. J Phys Educ Recreat Dance 58, $98-102$.

26. Sociedade Brasileira de Cardiologia, Sociedade Brasileira de Hipertensão \& Sociedade Brasileira de Nefrologia (2006) V Diretrizes Brasileiras de Hipertensão Arterial. Arq Bras Cardiol 87, 1-48.

27. Bouchard C, Tremblay A, Leblanc C et al. (1983) A method to assess energy expenditure in children and adults. $\mathrm{Am} \mathrm{J}$ Clin Nutr 37, 461-467.

28. World Health Organization (2010) Global Recommendations on Physical Activity for Health. Geneva: WHO.

29. Schisterman EF, Faraggi D, Reiser B et al. (2001) Statistical inference for the area under the receiver operating characteristic curve in the presence of random measurement error. Am J Epidemiol 154, 174-179.

30. Tudor-Locke C \& Bassett DR Jr (2004) How many steps/day are enough? Preliminary pedometer indices for public health. Sports Med 34, 1-8.

31. Freedman DS, Wang J, Ogden CL et al. (2007) The prediction of body fatness by BMI and skinfold thicknesses among children and adolescents. Ann Hum Biol 34, 183-194.

32. Sardinha LB, Going SB, Teixeira PJ et al. (1999) Receiver operating characteristic analysis of body mass index, triceps skinfold thickness, and arm girth for obesity screening in children and adolescents. Am J Clin Nutr $\mathbf{7 0}$, 1090-1095.

33. Ayatollahi SM \& Mostajabi F (2008) Triceps skinfold thickness centile charts in primary school children in Shiraz, Iran. Arch Iran Med 11, 210-213.

34. Bedogni G, Iughetti L, Ferrari M et al. (2003) Sensitivity and specificity of body mass index and skinfold thicknesses in detecting excess adiposity in children aged 8-12 years. Ann Hum Biol 30, 132-139.

35. Pecoraro P, Guida B, Caroli M et al. (2003) Body mass index and skinfold thickness versus bioimpedance analysis: fat mass prediction in children. Acta Diabetol 40, Suppl. 1, S278-S2781.

36. Lunardi CC \& Petroski EL (2008) Body mass index, waist circumference and skinfolds for predicting lipid abnormalities in 11 years old children. Arq Bras Endocrinol Metabol 52, 1009-1014.

37. Lee J, Ma S, Heng D et al. (2007) Should central obesity be an optional or essential component of the metabolic syndrome? Ischemic heart disease risk in the Singapore Cardiovascular Cohort Study. Diabetes Care 30, 343-347.

38. Taylor RW, Jones IE, Williams SM et al. (2000) Evaluation of waist circumference, waist-to-hip ratio, and the conicity index as screening tools for high trunk fat mass, as measured by dual-energy X-ray absorptiometry, in children aged 3-19 y. Am J Clin Nutr 72, 490-495.

39. Perez B, Landaeta-Jimenez M \& Vasquez M (2002) Fat distribution in Venezuelan children and adolescents estimated by the conicity index and waist/hip ratio. $A m J$ Hum Biol 14, 15-20.

40. Cali AM \& Caprio S (2009) Ectopic fat deposition and the metabolic syndrome in obese children and adolescents. Horm Res 71, Suppl.1, 2-7.

41. Thivel D, Malina RM, Isacco L et al. (2009) Metabolic syndrome in obese children and adolescents: dichotomous or continuous? Metab Syndr Relat Disord 7, 549-555.

42. Calcaterra V, De Amici M, Klersy C et al. (2009) Adiponectin, IL-10 and metabolic syndrome in obese children and adolescents. Acta Biomed 80, 117-123.

43. Ice CL, Murphy E, Minor VE et al. (2009) Metabolic syndrome in fifth grade children with acanthosis nigricans: results from the CARDIAC project. World J Pediatr 5, $23-30$. 
44. Agirbasli M, Agaoglu NB, Orak N et al. (2009) Sex hormones and metabolic syndrome in children and adolescents. Metabolism 58, 1256-1262.

45. Conde WL \& Monteiro CA (2006) Body mass index cutoff points for evaluation of nutritional status in Brazilian children and adolescents. J Pediatr (Rio J) 82, 266-272.
46. Wee BS, Poh BK, Bulgiba A et al. (2011) Risk of metabolic syndrome among children living in metropolitan Kuala Lumpur: a case control study. BMC Public Health 11, 333.

47. Stewart CP, Christian P, Schulze KJ et al. (2009) Antenatal micronutrient supplementation reduces metabolic syndrome in 6- to 8-year-old children in rural Nepal. J Nutr 139, $1575-1581$. 